\title{
Nutritional quality of two cyanobacteria: How rich is 'poor' food?
}

\author{
Katrin Schmidt ${ }^{1, *}$, Sigrún H. Jónasdóttir ${ }^{2}$ \\ 'Institut für Ostseeforschung an der Universität Rostock, Seestraße 15, D-18119 Rostock, Germany \\ ${ }^{2}$ Danish Institute for Fisheries Research, Department oi Marine and Coastal Ecology, Kavalergaarden 6, \\ DK-2920 Charlottenlund, Denmark
}

\begin{abstract}
Cyanobacteria have often been described to be nutritionally inadequate and to interfere with zooplankton feeding. In laboratory experiments we offered 2 cyanobacteria, a unicellular Microcystis aeruginosa strain and the filamentous Nodularia spumigena, to the calanoid copepod Acartaa tonsa as the sole diet and in food mixtures with the nutritious diatom Thalassiosira weissflogii. Egg production was used as criterion of food quality. The use of cyanobacteria alone was an insufficient diet. However, with increasing additions of $M$. aeruginosa and $N$. spumigena to the diatom, different effects were observed. Large additions of cyanobacteria resulted in lower egg production and often in elevated mortality of the females, but small additions of $M$ aeruginosa caused an increase of about $25 \%$ in egg production compared to a pure diatom diet. The influence of similar low concentrations of $N$. spumigena was weaker. We suppose that in the mixtures $A$. tonsa fed passively on $M$ a eruginosa, but not on the filaments of $N$ spumigend, and that ingested $M$. aeruginosa were used metabolically. As an additional test of the positive interactions between $M$. aeruginosa and $T$ weissflogii, different ratios of these species were offered to the copepods, while keeping the total food concentration constant. In mixtures egg production was higher than expected from the proportion of $T$ werssflogii. The highest egg production rates were observed at a 3:1 mixture of $T$. weissflogii to $M$. aeruginosa. We conclude that mono-specific food experiments may give a false impression of the nutritional quality of phytoplankton species. Cyanobacteria, which when fed alone prove to be poor food may supplement the diet of A. tonsa.
\end{abstract}

KEY WORDS: Microcystus aeruginosa - Nodularia spumigena . Cyanobacteria Nutritional quality . Calanoid copepods Acartia tonsa. Egg production

\section{INTRODUCTION}

Cyanobacteria periodically dominate the phytoplankton of many limnic, brackish and marine environments. According to most studies, characteristics like bad manageability of filaments, or nutritional inadequacy and toxicity (reviewed by Lampert 1987) make cyanobacteria 'poor' food for zooplankton (e.g. Porter \& Orcutt 1980, Lampert 1981, Holm \& Shapiro 1984, Nizan et al. 1986, Ahlgren et al. 1990). However, cyanobacteria species vary in toxicity and nutritional value (Lampert 1987), and zooplankton species have developed physiological and behavioral adaptations to the different characteristics of cyanobacteria. Thus,

·E-mail: katrin.schmidt@io-warnemuende.de certain zooplankton species are resistant to toxins of cyanobacteria (e.g. the rotifer Brachionus calyciflorus; Fulton \& Paerl 1987b), some non-discriminating filter feeders are too small for mechanical interferences with large colonial or filamentous cyanobacteria (e.g. small cladocerans; Fulton \& Paerl 1987b), other species avoid ingestion of endotoxic or nutritionally inadequate cyanobacteria by selective feeding (e.g. calanoid copepods; Fulton \& Paerl 1987b, DeMott 1989, DeMott et al. 1991), and other species are adapted to the nutritional composition of cyanobacteria (e.g. ratifers; Paerl 1988; harpacticoid copepods Macrosetella and Miracia; O'Neil \& Roman 1994).

The mechanisms by which calanoid copepods choose between cyanobacteria and high quality algae have been investigated in laboratory experiments (Fulton \& Paerl 1987a, b, 1988, DeMott 1989, DeMott \& 
Moxter 1991). The results of Fulton \& Paerl (1987a, b, 1988) suggest that the copepods Diaptomus reighardi and Eurytemora affinis avoid ingestion of unicellular and colonial Microcystis aeruginosa (cyanobacteria) in mixtures with the nutritious chlorophyte Chlamydomonas reinhardi by chemosensory means. DeMott \& Moxter (1991) offered a variety of cyanobacteria of different size, morphology and toxicity in mixtures with $C$. reinhardi to the copepod Diaptomus birgei and observed that the planktonic cyanobacteria were strongly rejected. On the other hand, ingestion of appreciable quantities of cyanobacteria has been documented for freshwater copepods in the field (e.g. Schindler 1971, Infante 1978, Haney \& Trout 1985. Burns et al. 1989).

In the Pomeranian Bay (southern Baltic Sea), which is influenced by continuous freshwater input from the Oder River, Poland/Germany, the neritic calanoid copepods Acartia bifilosa and A. tonsa co-exist during the summer months with a diverse phytoplankton community dominated by cyanobacteria, chlorophytes and diatoms (Pollehne et al. 1995). Pigment analyses have shown that the ambient composition of the phytoplankton population is also reflected in the gut contents of the copepods (Meyer-Harms 1996). Therefore, cyanobacteria were ingested by Acartia sp. and it seems that the copepods are well adapted to the changing diet which occurs in the area (Pollehne et al. 1995). On the other hand, the changing diet may be the main reason for the observed high variability in egg production rates of Acartia sp. in the Pomeranian Bay (Schmidt unpubl.). Consequently, there are 2 aspects to consider. One is the ingestion or rejection of cyanobacteria by zooplankton, and the other is the food quality of ingested cyanobacteria, which is ultimately shown in physiological responses like survival, growth and reproduction. The latter aspect was tested by Burns \& Xu (1990), who found reasonable survival and reproduction of the calanoid copepod Boeckella spp. fed with pure cultures of filamentous cyanobacteria. In contrast, cyanobacteria were unsuitable as the only food source for the development of the copepod Eudiaptomus gracilis (Santer 1994). In nature, however, cyanobacteria co-exist with other phytoplankton groups, and the diet of zooplankton is also diverse during blooms of cyanobacteria.

In the present study we combined the approaches of the described laboratory experiments, i.e. we offered cyanobacteria in mixtures and we used an integrated parameter to examine the nutritional value (egg production of Acartia tonsa). The effect of cyanobacteria as a mono-specific food was compared with the interplay of cyanobacteria and another species, which is known to be nutritious, in a combined diet. Following the phytoplankton compositions of the Pomeranian Bay, the unicellular Microcystis aeruginosa and the filamentous Nodularia spumigena were mixed with the diatom Thalassiosira weissflogii in a broad range of absolute and relative concentrations. To distinguish a plausible effect of high food concentration from a effect of food quality, an additional experiment was carried out using a chlorophyte (Scenedesmus acutus) instead of cyanobacteria in a mixture with the diatom.

\section{MATERIALS AND METHODS}

Cultures. Acartia tonsa was grown in $0.5 \mu \mathrm{m}$ filtered seawater, salinity $(\mathrm{S})=32$, enriched with a super abundant concentration of Rhodomonas baltica (Støttrup et al. 1986). Due to planned experiments with limnic/brackish-water phytoplankton, the females were gradually adapted to $S=15$ within $5 \mathrm{~d}$ after maturation.

The autotrophs were grown in semi-continuous batch cultures using $f / 2$ growth medium at $S=10$, a temperature of $18 \pm 1^{\circ} \mathrm{C}$ and continuous illumination. The dilution rates of the cultures were kept constant to ensure exponential growth throughout the experiment. The cultures were not auxenic. Species used as food in the experiments were the diatom Thalassiosira weissflogii; the cyanobacteria Microcystis aeruginosa and Nodularia spumigena, and the chlorophyte Scenedesmus acutus. Table 1 lists the specifics of these autotrophs.

Table 1. Characterıstics of the autotroph species used in this study. Thalassiosira welssflogn (TW), Microcystis aeruginosa (MA),

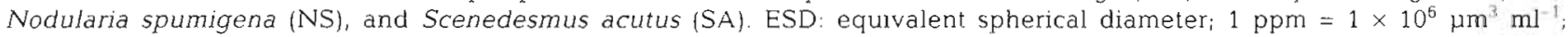
G: Culture Collection Goltingen, Germany; X: Collection of Kiel University, Germany

\begin{tabular}{|c|c|c|c|c|c|c|}
\hline Species & Form & $\operatorname{ESD}(\mu \mathrm{m})$ & $\mu \mathrm{gCl} \mathrm{l}^{-1} / \mathrm{ppm}$ & C:chl a & Toxicity & Source/strain no \\
\hline TW & Unicellular & 15 & -200 & & - & G B122.79 \\
\hline MA & Unicellular d & 4.5 & $\sim 200$ & & Not tested & G B 46.80 \\
\hline NS & Filaments & 8 (thickness) $\times 1000$ (length) & & 80 & Not tested & X SN 34 \\
\hline $\mathrm{SA}$ & $(2,3) 4$ cells & 16 & -180 & & - & G 276-11 \\
\hline
\end{tabular}


Experiments. Volume based concentrations of food suspensions were set using a particle counter (ELZONE 180, Particle Data, Inc., fitted with $120 \mu \mathrm{m}$ orifice). In the case of Nodularia spumigena, which is a filamentous colony, the same volume of the culture was used every day and the concentration was subsequently determined based on chlorophyll a (chl a) content. The experiments lasted for $7 \mathrm{~d}$ and were performed at $18 \pm 1^{\circ} \mathrm{C}$ and $\mathrm{S}=15$. Dim light conditions $\left(<0.18 \mu \mathrm{E} \mathrm{m}^{-2} \mathrm{~s}^{-1}\right)$ were used to prevent the growth of phytoplankton. Three $1 \mathrm{l}$ bottles each containing 15 females were used for each diet. The bottles were placed on a $0.5 \mathrm{rpm}$ rotating wheel. After $24 \mathrm{~h}$, females and eggs were screened out by means of 180 and $40 \mu \mathrm{m}$ sieves, respectively. The living females were counted and transferred to a fresh food suspension in a new bottle. Eggs were fixed with Lugol's solution for later counting. Fecal pellets were not quantified

To investigate the effects of food quality, egg production rates of Acartia tonsa were measured in 3 types of experiments.

1. Mono-specific food experiments: Four different food species (Table 1) were offered at a concentration of $5 \mathrm{ppm}\left(5 \times 10^{6} \mathrm{\mu m}^{3} \mathrm{ml}^{-1}\right)$. In addition to egg production, grazing rates were estimated at Days 1, 3 and 5 . Clearance and ingestion rates were calculated (Frost 1972) based on volume concentrations for Thalassiosira weissflogii, Microcystis aeruginosa and Sceneclesmus acutus and on chl a concentration for Nodularia spumigena.

2. Mixture/addition experiments: Concentrations of $0.75,1.5,3$ and $6 \mathrm{ppm}$ (Microcystis aeruginosa and Scenedesmus acutus) or $\sim 0.38,0.75,1.5$ and $3 \mathrm{ppm}$ (Nodularia spumigena) were each added to a concentration of $1.5 \mathrm{ppm}$ of Thalassiosira weissflogii.

3. Mixture/ratio experiments: Microcystis aeruginosa and Thalassiosira weissflogii were mixed according to the ratios $1: 0,3: 1,1: 1,1: 3$, and $0: 1$. Two experiments were conducted, with total concentrations of the mixtures at $1.5 \mathrm{ppm}$ in the first experiment and at $3 \mathrm{ppm}$ in the second. During the $24 \mathrm{~h}$ incubations, the mean concentrations of neither species changed much. Thus, the shift of ratio resulting from different growth and grazing rates was generally not more than 10\% (in some exceptions up to $30 \%$ ). A schematic presentation of idealized results in a ratio experiment is shown in Fig. 1.

Chemical analysis. Samples of the cultures were filtered onto combusted GF/F filters for later $\mathrm{C} / \mathrm{N}$ and chl $a$ analyses. Filters were stored at $-80^{\circ} \mathrm{C}$. C/N analyses were carried out with a Carlo Erba/Fisons $1108 \mathrm{CHN}$ elemental analyzer. Chl a concentrations were determined using a fluoro-colorimeter (Amico).

Statistics. One-way analysis of variance (ANOVA) procedures were used to test the significance of differences in egg production rates between treatments. Generally, variances across different treatments were

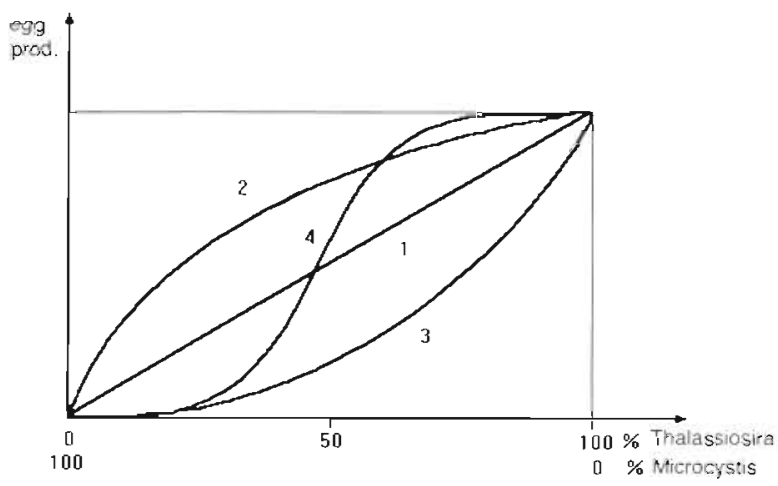

Fig. 1 Schematic presentation of possible results in a ratio experiment. Different proportions of Microcystis aeruginosa were mixed with a nutritious food species (Thalassiosıra weissflogii) at a constant unsaturated food concentration. Hypotheses: (1) $M$. aeruginosa has no influence. The egg production of Acartia tonsa is a function of the concentration of $T$. weissflogii. (2) $M$. aeruginosa has a positive effect on egg production. (3) $M$. aeruginosa has a negative effect on egg production. (4) $M$. aeruginosa has a negative as well as a positive effect depending on the ratio (1 example)

equal ( $p>0.05$; Bartlett's test). Means were analysed with a multiple range test (test of 'least significant difference', LSD)

\section{RESULTS}

\section{Mono-specific food experiments}

There were significant differences in egg production depending on food species (1-way ANOVA, $F=205.3$, $p<0.0001$ ). Egg production rates were high on a diet of Thalassiosira weissflogii, gradually decreased for females fed Scenedesmus acutus, and there was almost no egg production on both cyanobacteria species (Fig. 2, Table 2).

Mean ingestion rates at a food concentration of $5 \mathrm{ppm}$ were $770 \mathrm{ng} \mathrm{C}(\mu \mathrm{g} \mathrm{dw} \mathrm{d})^{-1}$ for females fed Thalassiosira weissflogii and $530 \mathrm{ng} \mathrm{C}(\mu \mathrm{g} \mathrm{dw} d)^{-1}$ for females fed Scenedesmus acutus. Clearance of Microcystis aeruginosa and Nodularia spumigena by Acartia tonsa was not detected, although different food concentrations were tested $(0.75,1.5,3$ and $5 \mathrm{ppm})$. Additionally, fecal pellet production was not noticed, which further supports the notion that $A$. tonsa did not ingest these cyanobacteria in significant amounts when offered alone.

\section{Mixture/addition experiment}

We found significant differences in egg production rates depending on the concentrations of Microcystis aeruginosa, Nodularia spumigena or Scenedesmus 


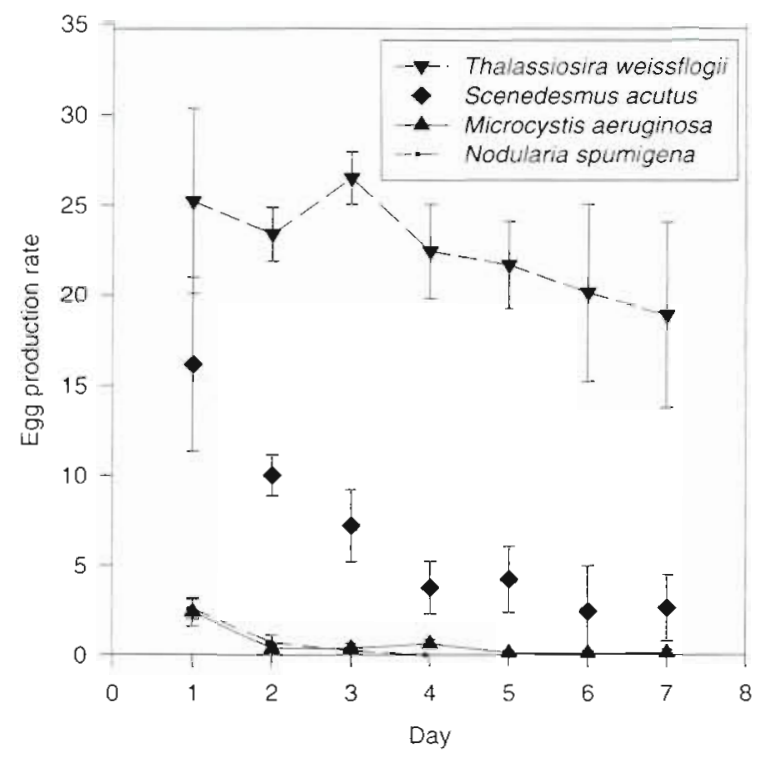

Fig. 2. Egg pruduction rates of Acartia tonsa females (eggs ind ${ }^{-1} \mathrm{~d}^{-1} \pm 1 \mathrm{SD}, \mathrm{n}=3$ ) fed 4 different autotroph species at a food concentration of $5 \times 10^{6} \mu^{3} \mathrm{ml}^{-1}$ as a function of time (days from start of the experiment)

acutus added (1-way ANOVA, $M$. aeruginosa: $F=65.2$, $\mathrm{p}<0.0001 ; N$. spumigena: $F=2.9, \mathrm{p}=0.0241 ; \mathrm{S}$. acutus: $F=5.8, \mathrm{p}=0.0003$ ). The apparent increase of egg production rates with small additions of $M$. aeruginosa and $N$. spumigena to the pure diatom diet (Fig. 3a, b) was significant in the case of $M$. aeruginosa during the first $4 \mathrm{~d}$ of the experiment (Table 2, Days 1 to 4 ). On the other hand, high concentrations of $M$. aeruginosa and $N$. spumigena caused a reduction of the egg production rate (Fig. 3a, b, Table 2). A comparison of the mean egg production rates between the pure diatom diet and the mixtures (Table 2) suggests that $M$. aeruginosa had a stronger positive as well as negative influence on Acartia tonsa than $N$. spumigena.

Egg production was unaffected or increased at low as woll as high concentrations of Scenedesmus acutus (Fig. 3c, Table 2). On Day 2 of the S. acutus mixture experiment, the culture of Thalassiosira weissflogii broke down and we had to switch to a slow-growing back-up culture. The following decrease in egg production rates with the pure $T$. weissflogii diet were compensated for in the mixtures (Fig. 3c, Table 2: Days 3 to 6 ).

Fig. 3. Egg production rates of Acartia tonsa females leggs ind ${ }^{-1} d^{-1} \pm 1 \mathrm{SD}, \mathrm{n}=3$ ) fed mixtures of Thalassiosira weissflogit $\left(1.5 \times 10^{6} \mathrm{\mu m}^{3} \mathrm{ml}^{-1} ; \rightarrow-\right)$ and (a) Microcystis aeruginosa $(6,3$,

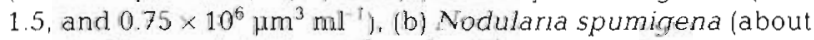

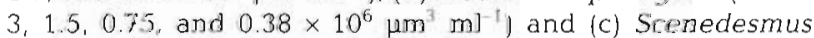
acutus $\left(6,3,1.5\right.$, and $\left.0.75 \times 10^{6} \mathrm{\mu m}^{3} \mathrm{ml}^{-1}\right)$ as a function of time. $(-\ldots,-,,-\cdots, \ldots, \ldots)$ Respectively decreasing concentrations added for each species
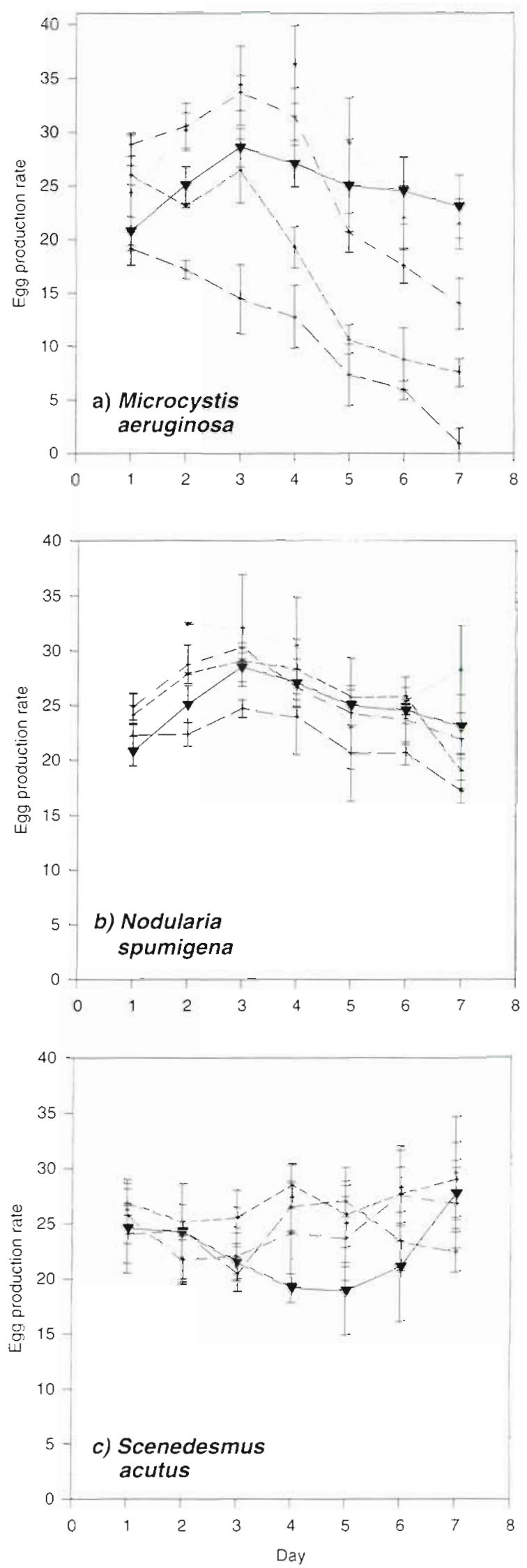
Table 2. Summary of results and statıstical analyses. Average egg production rate of Acartia tonsa fed pure Thalassiosira welss flogij (TW) includes all measured egg production rates during 1 experiment (i.e. 3 parallels over 4 or 7 d). Average egg production rates on other diets [including Scenedesmus acutus (SA), Microcystis aeruginosa (MA), Nodularia spumigena (NS)] in each experiment were calculated in the same way and normalized with respect to rates obtained with the pure diatom diet. For each experiment, non-significant differences between the average egg production rates on different diets are indicated by the same letter (LSD test). In 3 cases the statistical analyses were repeated for selected days of the experiment (explanations given in 'Results')

\begin{tabular}{|c|c|c|c|c|c|}
\hline Expt & $\begin{array}{l}\text { Species, } \\
\text { addition (ppm), } \\
\text { or ratio }\end{array}$ & $\begin{array}{l}\text { Avg egg prod. } \\
\text { (eggs ind } \mathrm{d}^{-1} \mathrm{~d}^{-1} \text { ) } \\
\text { on pure } T \text { weissflogii }\end{array}$ & $\begin{array}{l}\text { Avg. egg prod. } \\
\text { as } \% \text { of pure } \\
T \text { weissflogii }\end{array}$ & $\begin{array}{c}\text { Homogeneous } \\
\text { groups } \\
(95 \% \text { LSD })\end{array}$ & $\begin{array}{l}\text { Mortality of } \\
\text { females } \\
\text { after } 7 \mathrm{~d}(\%)\end{array}$ \\
\hline $\begin{array}{l}\text { Mono-specific } \\
5 \text { ppm conc. } \\
(7 \mathrm{~d})\end{array}$ & $\begin{array}{l}\text { T. weissflogii } \\
\text { S. aculus } \\
M \text {. aeruginosa } \\
\text { N. spumigena }\end{array}$ & 23 & $\begin{array}{r}100 \\
29 \\
3 \\
2\end{array}$ & $\begin{array}{l}\mathrm{a} \\
\mathrm{b} \\
\mathrm{c} \\
\mathrm{c}\end{array}$ & $\begin{array}{l}47 \\
60 \\
70 \\
90\end{array}$ \\
\hline $\begin{array}{l}\text { Addition } \\
\text { MA to TW (7 d) }\end{array}$ & $\begin{array}{l}+0.75 \\
+1.5 \\
+0 \\
+3 \\
+6\end{array}$ & 25 & $\begin{array}{r}114 \\
102 \\
100 \\
70 \\
45\end{array}$ & $\begin{array}{l}\mathrm{a} \\
\mathrm{a} \\
\mathrm{a} \\
\mathrm{b} \\
\mathrm{c}\end{array}$ & $\begin{array}{r}8 \\
28 \\
40 \\
82 \\
90\end{array}$ \\
\hline MA to TW (Days 1-4) & $\begin{array}{l}+0.75 \\
+1.5 \\
+0 \\
+3 \\
+6\end{array}$ & 25 & $\begin{array}{r}124 \\
123 \\
100 \\
93 \\
63\end{array}$ & $\begin{array}{l}\mathrm{a} \\
\mathrm{a} \\
\mathrm{b} \\
\mathrm{b} \\
\mathrm{c}\end{array}$ & \\
\hline NS to TW $(7 \mathrm{~d})$ & $\begin{array}{l}+0.4 \\
+0 \\
+0.75 \\
+1.5 \\
+3\end{array}$ & 25 & $\begin{array}{r}104 \\
100 \\
99 \\
98 \\
87\end{array}$ & $\begin{array}{l}\mathrm{a} \\
\mathrm{a} \\
\mathrm{a} \\
\mathrm{a} \\
\mathrm{b}\end{array}$ & $\begin{array}{l}40 \\
40 \\
30 \\
22 \\
25\end{array}$ \\
\hline NS to TW (Days 1-4) & $\begin{array}{l}+0.4 \\
+0.75 \\
+1.5 \\
+0 \\
+3\end{array}$ & 25 & $\begin{array}{r}109 \\
109 \\
101 \\
100 \\
92\end{array}$ & $\begin{array}{l}a \\
a \\
a, b \\
a, b \\
b\end{array}$ & \\
\hline SA to TW $(7 d)$ & $\begin{array}{l}+3 \\
+0.75 \\
+1.5 \\
+6 \\
+0\end{array}$ & 22 & $\begin{array}{l}120 \\
117 \\
109 \\
107 \\
100\end{array}$ & $\begin{array}{l}a \\
a, b \\
b, c \\
c \\
c\end{array}$ & $\begin{array}{l}30 \\
24 \\
18 \\
20 \\
50\end{array}$ \\
\hline SA to TW (Days 3-6) & $\begin{array}{l}+3 \\
+0.75 \\
+1.5 \\
+6 \\
+0\end{array}$ & 20 & $\begin{array}{l}132 \\
132 \\
121 \\
121 \\
100\end{array}$ & $\begin{array}{l}a \\
a \\
a \\
a \\
b\end{array}$ & \\
\hline $\begin{array}{l}\text { Ratio } \\
\text { MA:TW } \\
1.5 \text { ppm conc. }(7 \mathrm{~d})\end{array}$ & $\begin{array}{l}1: 3 \\
0: 1 \\
1: 1 \\
3: 1 \\
1: 0\end{array}$ & 24 & $\begin{array}{r}102 \\
100 \\
85 \\
51 \\
9\end{array}$ & $\begin{array}{l}a \\
a \\
b \\
c \\
d\end{array}$ & $\begin{array}{l}49 \\
40 \\
43 \\
73 \\
83\end{array}$ \\
\hline $\begin{array}{l}\text { MA:TW } \\
3 \text { ppm conc. }(7 \mathrm{~d})\end{array}$ & $\begin{array}{l}1: 3 \\
0: 1 \\
1: 1 \\
3: 1 \\
1: 0\end{array}$ & 48 & $\begin{array}{r}108 \\
100 \\
87 \\
61 \\
9\end{array}$ & $\begin{array}{l}a \\
a \\
b \\
c \\
d\end{array}$ & $\begin{array}{l}13 \\
16 \\
26 \\
81 \\
80\end{array}$ \\
\hline
\end{tabular}

\section{Mixture/ratio experiment}

Significant differences in egg production rates were observed depending on the ratio of Thalassiosira weissflogii and Microcystis aeruginosa at a constant total food concentration (1-way ANOVA; 1.5 ppm: $F=$
90.5, $\mathrm{p}<0.000 ; 3 \mathrm{ppm}: F=138.4, \mathrm{p}<0.0001)$. Egg production rates of Arctica tonsa which were fed pure $M$. aeruginosa diet or mixtures were normalized with respect to those fed pure $T$. weissflogii food suspension (Figs. 4 \& 5). With 1 exception, the egg production rates were higher than expected from the pure con- 


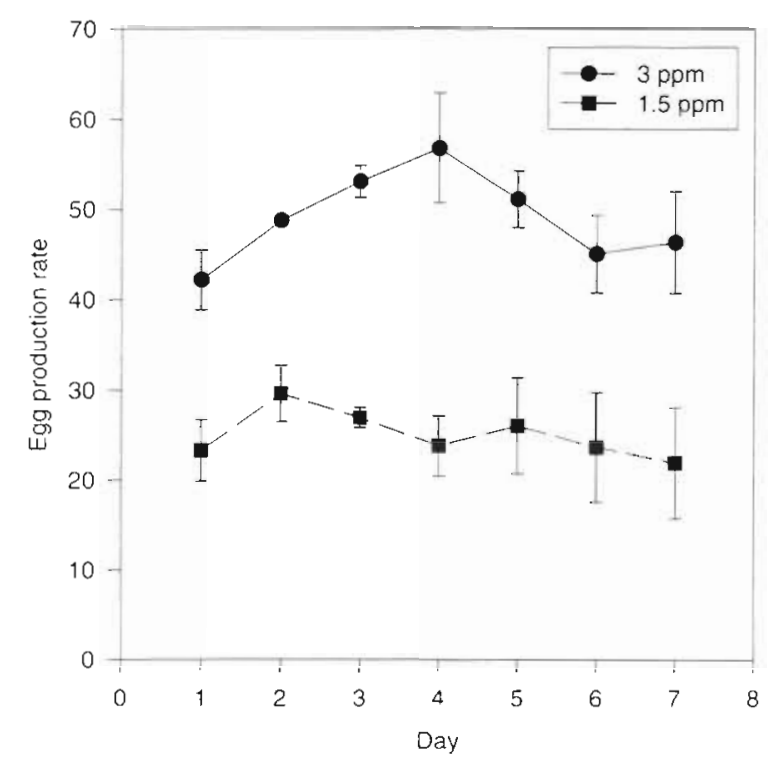

Fig. 4. Egg production rates of Acartia tonsa females (eggs ind $^{-1} \mathrm{~d}^{-1} \pm 1 \mathrm{SD}, \mathrm{n}=3$ ) fed Thalassiosira weissflogii at 1.5 and $3 \times 10^{6} \mu \mathrm{m}^{3} \mathrm{ml}^{-1}$ during a $7 \mathrm{~d}$ experiment

centration of $T$. weissflogii in all mixtures and during the entire course of the experiment (Fig. 5). That is, $A$. tonsa females profited from the presence of $M$. aeruginosa in the mixtures. Observations from Jónasdóttir (1994, her Fig. 1) and the results in Fig. 4 allow the assumption that egg production of $A$. tonsa fed pure $T$. weissflogii is a linear function of the food concentration up to $3 \mathrm{ppm}$. The line in Fig. 5 marks this linear function (see also Fig. 1). From the absolute data (Table 3). egg production rates were higher at the low proportion of $M$. aeruginosa compared to the pure diatom diet, but at higher proportions of $M$. aeruginosa egg production was lower $(25 \% \leq 0 \%<50 \%<75 \%<100 \%)$. However, the difference between the mixture of $25 \%$ $M$. aeruginosa $/ 75 \% \quad T$. weissflogii and the pure $T$ weissflogii was significant only for Days 2 to 4 of the experiment (total concentration: $3 \mathrm{ppm}$ ).

\section{Feeding history}

At least on the first day of the experiment the egg production rates were affected by the previous food alga (Rhodomonas baltica) (Fig. 2). However, reserves of some essential nutrients may enhance the egg production over a longer period. The period of the $R$. baltica influence was not determined and appeared to depend on the current diet. In the 'addition experiments' the concentration of the nutritious food was sufficient to result in high egg production, and we suppose that reserves from $R$. baltica did not have a significant effect. In contrast, in the 'ratio experiments' (Fig. 5a, b,
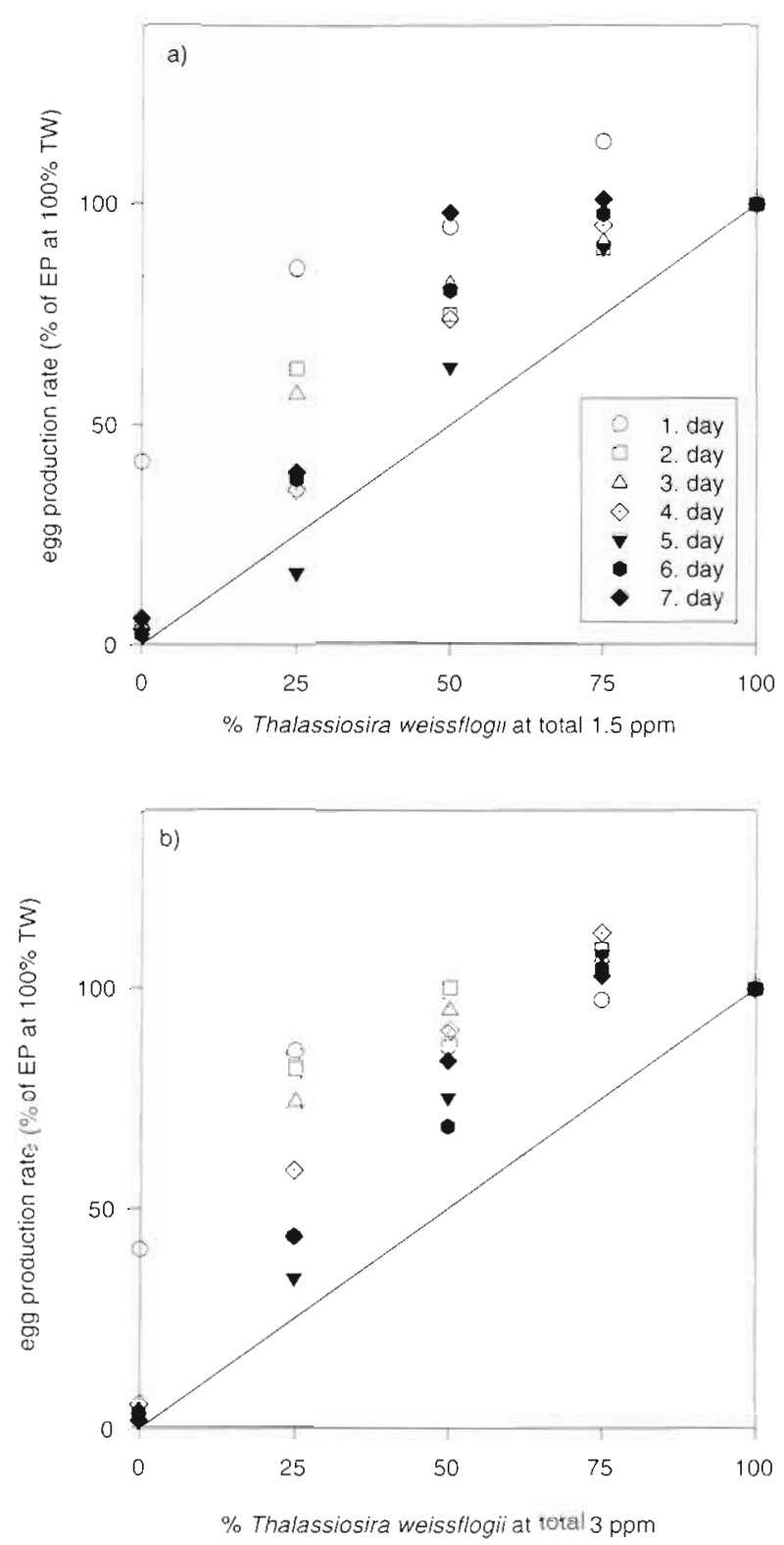

Fig. 5. Acartia tonsa egg production rates in mixtures of Microcystis aeruginosa and Thalasslosira weissflogii in ratios of $1: 0,3: 1,1: 1,1: 3$ and $0: 1$ as percentage of the dally egg production rate (EP) on the pure $T$ weissflogii (TW) diet $(0: 1$; see Fig. 4). A total food concentration of (a) $1.5 \times 10^{6} \mu \mathrm{m}^{3} \mathrm{ml}^{-1}$ and (b) $3.0 \times 10^{6} \mu^{3} \mathrm{ml}^{-1}$ Solid lines represent the expected egg production rates as a linear function of the $T$ weissflogiiconcentration (see also Fig. 1)

Table 3) at the low proportion of Thalassiosira weissflogii, the egg production rate decreased continuously during the first $4 \mathrm{~d}$. At a $50 \%$ proportion the effect was already weaker, and it was not noticeable at high proportions of $T$. weissflogii. Thus, the feeding history was important at low proportions of $T$ weissflogii, but should otherwise not be over-emphasized. 
Table 3. Egg production rates (eggs $n \mathrm{nd}^{-1} \mathrm{~d}^{-1} \pm 1 \mathrm{SD}, \mathrm{n}=3$ ) of Acartia tonsa fed mixtures of Microcystis aeruginosa and Thalassiosira weissflogii in ratios of 1:0, 3:1, 1:1,1:3, and 0:1 in total food concentrations of 1.5 and $3.0 \mathrm{ppm}$

\begin{tabular}{|c|c|c|c|c|c|}
\hline Day & M. aeruginosa & $3: 1$ & $1: 1$ & $1: 3$ & $T$ werssflogi \\
\hline \multicolumn{6}{|c|}{$1.5 \mathrm{ppm}$} \\
\hline 1 & $10 \pm 1$ & $20 \pm 2$ & $22 \pm 1$ & $27 \pm 1$ & $24 \pm 4$ \\
\hline 2 & $1 \pm 1$ & $19 \pm 1$ & $22 \pm 2$ & $27 \pm 1$ & $28 \pm 1$ \\
\hline 3 & $1 \pm 1$ & $15 \pm 1$ & $22 \pm 3$ & $25 \pm 3$ & $27 \pm 1$ \\
\hline 4 & $1 \pm 1$ & $8 \pm 2$ & $18 \pm 3$ & $23 \pm 3$ & $26 \pm 2$ \\
\hline 5 & $1 \pm 1$ & $4 \pm 1$ & $16 \pm 6$ & $24 \pm 0$ & $23 \pm 0$ \\
\hline 6 & $1 \pm 1$ & $9 \pm 4$ & $19 \pm 6$ & $23 \pm 3$ & $20 \pm 1$ \\
\hline 7 & $1 \pm 1$ & $8 \pm 6$ & $21 \pm 10$ & $22 \pm 3$ & $19 \pm 6$ \\
\hline \multicolumn{6}{|c|}{$3.0 \mathrm{ppm}$} \\
\hline 1 & $17 \pm 2$ & $36 \pm 2$ & $37 \pm 5$ & $41 \pm 1$ & $42 \pm 3$ \\
\hline 2 & $2 \pm 1$ & $40 \pm 2$ & $48 \pm 2$ & $53 \pm 3$ & $49 \pm 1$ \\
\hline 3 & $2 \pm 0$ & $39 \pm 2$ & $50 \pm 3$ & $57 \pm 2$ & $53 \pm 2$ \\
\hline 4 & $3 \pm 0$ & $33 \pm 5$ & $51 \pm 5$ & $64 \pm 4$ & $57 \pm 6$ \\
\hline 5 & $1 \pm 1$ & $18 \pm 3$ & $38 \pm 4$ & $55 \pm 9$ & $51 \pm 3$ \\
\hline 6 & $2 \pm 2$ & $20 \pm 7$ & $31 \pm 3$ & $47 \pm 4$ & $45 \pm 4$ \\
\hline 7 & $1 \pm 1$ & $20 \pm 5$ & $39 \pm 6$ & $48 \pm 5$ & $46 \pm 6$ \\
\hline
\end{tabular}

\section{Mortality of females}

Mortality of females (\%) after $7 \mathrm{~d}$ is shown in Table 2. In most of our experiments mortality was high compared to results in similar investigations (e.g Jónasdóttir \& Kiørboe 1996). We attribute the high mortality, at least partly, to the pre-experimental salinity adaptation 'stress' experienced by the females. It is also noticeable that the highest mortality $(>70 \%)$ was observed in the mixture experiments with high concentrations or ratios of Microcystis aeruginosa and low egg production. A toxic effect of $M$. aeruginosa can be assumed; however, another explanation would be starvation of the females. In some of the mixture experiments mortality of females was lower than in the pure Thalassiosira weissflogii diet.

\section{DISCUSSION}

Egg production of continuously reproducing copepods integrates all effects of the diet, i.e. those related to ingestion (interference of the ingestion of other food, ingestion/rejection of cyanobacteria), toxicity, and assimilation. These intermediate parameters were not measured in the present study (with the exception of the ingestion in mono-specific food experiments) and egg production rates will be discussed on the basis of the offered food, not on the basis of the ingested food.

The ultimate criterion of reproductive success, the hatching of eggs, was not investigated. The growth of juveniles would require a separate study, since developing stages have different demands on food size and quality.

\section{Cyanobacteria as the only food source}

Acartia tonsa could not maintain its egg production either with a small-cell (Microcystis aeruginosa) or with a filamentous cyanobacteria (Nodularia spumigena). The fact that calanoid copepods of the taxon Boeckella spp. have shown good reproduction when fed pure cultures of filamentous cyanobacteria (Burns \& Xu 1990) confirms differences in the ability to live on cyanobacteria within 1 zooplankton group. In the case of the cyanobacteria species offered in our experiments, $A$. tonsa already failed at the point of ingestion. Sensitivity of $A$. tonsa to the 'bad taste' of planktonic cyanobacteria (DeMott \& Moxter 1991) may have been a reason. There are also indications that avoidance could be caused by the special morphologies of $M$. aeruginosa and $N$. spumigena. Vanderploeg et al. (1988) noticed that the genus Acartia cannot effectively handle elongated species and this probably applies also to fresh $N$. spumigena filaments. The small cells of $M$. aeruginosa, on the other hand, may not stimulate a filtering current at all. This is supported by our observation in a previous experiment that an unidentified centric diatom of similar size $(5 \mu \mathrm{m})$ was also not ingested by $A$. tonsa (authors' unpubl. data). The chlorophyte Scenedesmus acutus was ingested when offered as the only food source, but supported only low egg production in A. tonsa.

\section{Eifects of cyanobacteria in a mixed diet}

Large additions of cyanobacteria to a diet of mediumsized diatoms may cause a decrease in egg production at different intermediate steps of food processing. 


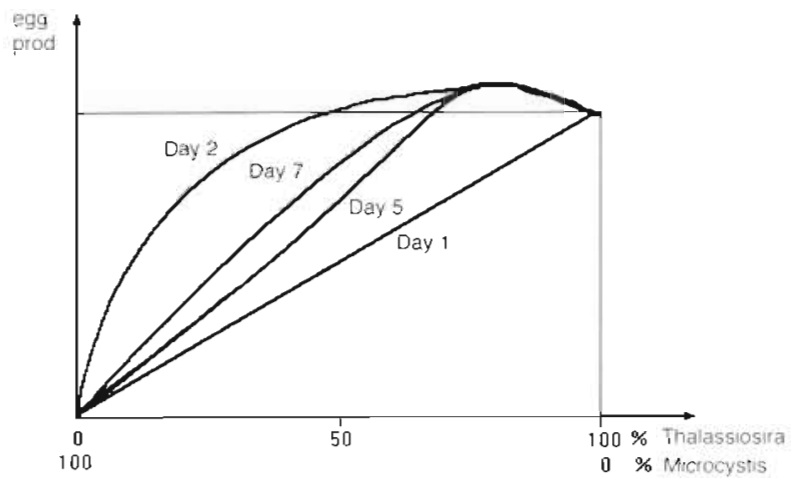

Fig. 6. A schematic presentation of our results in the ratio experiment; Days 2, 5 and 7 (compare Fig. 1). At all tested mixtures the measured egg production rates were above line 1 and indicate a positive effect of Microcystis aeruginosa on egg production. The nutritional benefit from $M$ aeruginosa is best shown at a proportion of $75 \%$ Thalassiosira weissflogii to $25 \% M$. aeruginosa. This mixture has a nutritional advantage compared to the pure diatom. During the first $4 \mathrm{~d}$ a running oul of reserves from Rhodomonas baltuca was evident at low and median proportions of $T$ weissflogii, but not at high proportions

Cyanobacteria can reduce filtering rates on the cooccurring nutritious food, e.g. by clogging the appendages, and/or can be hidden among a larger mass of high-quality food and ingested as well (Paffenhofer \& Van Sant 1985) The former effect was noticed for the copepod Diaptomus reighardi in a suspension of about 3 ppm of Microcystis aeruginosa (Fulton \& Paerl $1987 \mathrm{~b}$ ). A high proportion of passively ingested cyanobacteria (especially in the case of the unicellular $M$. aeruginosa) may either contain a critical dose of toxins, or their assimilation may result in a nutritional imbalance compared to the pure diatom diet. It is remarkable that the same concentration of the chlorophyte Scenedesmus acutus had no negative effect on egg production of Acartia tonsa.

Small additions of cyanobacteria to a diatom improved the egg production in Acartia tonsa. The effect may have occurred at 2 levels: a stimulated feeding on the co-occurring nutritious food species, or ingestion and assimilation of the cyanobacteria in a proportion which improves the nutritional balance compared to the pure diatom. Both effects were noticed by Roman (1984), who fed A. tonsa with a mixture of Thalassiosira weissflogii and macrophyte-detritus. In our study there were higher egg production rates in mixtures with small additions of Microcystis aeruginosa than in mixtures with small additions of Nodularia spumigena. We conclude that $M$ a aruginosa were accumulated, ingested and successfully assimilated during suspension feeding on the diatom, while $N$. spumigena filaments were not ingested amd assimilated in the same manner.
The ratio experiments confirmed that Acartia tonsa benefitted from the presence of Microcystis aeruginosa in food mixtures (Fig. 6). A replacement of one quarter of Thalassiosira weissflogii by $M$. aeruginosa caused an increase in egg production compared to the same concentration of the pure diatom. Accordingly, Rothhaupt (1991) observed that, while a filamentous cyanobacteria species alone did not support population growth of the rotifer Brachionus rubens, a 1:1 mixture of a nutritious chlorophyte and the cyanobacterium was a more superior food than an equal concentration of the chlorophyte alone.

\section{Nutritional quality of cyanobacteria}

Our results suggest that the nutritional composition of Thalassiosira weissflogii is adequate but not optimal for Acartia tonsa egg production, and that the nutritional composition of Microcystis aeruginosa was inadequate alone, but in small doses supplemented the diatom.

The lack of long-chained polyunsaturated fatty acids (PUFA) in cyanobacteria has been suggested to be the reason of their nutritional inadequacy for zooplankton (Ahlgren et al. 1990, Ahlgren 1993). Long-chained PUFA are essential components of the diet and have been considered as indicators of high nutritional quality (e.g. Watanabe et al. 1983, Enright et al. 1986. Volkman et al. 1989, Ahlgren et al. 1990, Jónasdóttir 1994, Jónasdóttir \& Kiorboe 1996). A high content of longchained PUFA is characteristic for both autotrophic flagellates and diatoms. In Microcystis areruginosa no 22:6w3 PUFA, only traces of 20:5 133 , and a low content of 18:303 fatty acids were detected (Ahlgren et al. 1990, 1992). However, besides long-chained PUFA other nutritional components are important in maturation and reproduction of crustaceans, e.g. amino acids for syntheses of peptide hormones and egg yolk proteins (Harrison 1990). Cyanobacteria have been found to have a very high content of amino acids (Ahlgren et al. 1992). M. aeruginosa has a higher proportion of essential amino acids than Thalassiosira weissflogii. $44 \%$ (Ahlgren et al. 1992) versus 35\% (Cowie \& Hedges 1996) respectively. Protein comprises about $40 \%$ of dry weight in $M$. aeruginosa (Ahlgren et al. 1992) and $30 \%$ in $T$. weissflogii (Nguyen \& Harvey 1994). Additionally, diatoms contain less glucose but more fucose and rhamnose compared to other autotrophs (Whyte \& Nagata 1990, Brown 1991). A high content of glucose as an immediate energy source could form an efficient energy supply for the basic subsistence of the females ingesting cyanobacteria.

In the 'ratio experiment' egg production rate was in some cases distinctly higher than expected from the 
concentration of the diatom. At high proportions of the diatom the 'excess' egg production was almost constant, but at a low proportion of the diatom, egg production decreased with time. We assume that in experiments with a low concentration of Thalassiosira weissflogii the high egg production rates were caused by reserves of essential nutrients (e.g. fatty acids) from Rhodomonas baltica, on which Acartia tonsa had been grown prior to the experiments

Mixtures with Scenedesmus acutus were not as effective as small additions of Microcystis aeruginosa. Only during the stationary growth phase of the diatom did the added chlorophyte cause an increase in egg production. Kleppel \& Burkart (1995) remarked that the nutritional value of a food is not static but varies with nutritional composition of other foods in the environment.

It should not be disregarded that in nature the relationship between cyanobacteria and mesozooplankton can be even more complex. Hoppe (1981) observed that the network of Nodularia spumigena filaments attracts a wide range of small organisms including bacteria, flagellates and ciliates. These rich agglomerates may serve as an optimal food source for copepods. Field investigations of Meyer-Harms (1996) imply that feeding of Acartia bifilosa on filamentous cyanobacteria depends on the physiological status of the bloom. Increasing ingestion rates were observed during the regressing phase of the cyanobacteria bloom as filaments were more degenerated and colonized by heterotrophic microorganisms.

\section{Conclusion}

This study clearly shows that cyanobacteria are not generally poor food, but that their biochemical composition may complement certain diets. The positive effect only became evident in food mixtures which correspond to field conditions better than monospecific food. On the other hand, the impairing effect of high concentrations of cyanobacteria has been confirmed. The findings may help explain field observations where egg production is variable independent of temperature and sometimes negatively correlated to the bulk-parameter chl a.

Acknowledgements. The present study was funded by the German Bundesminister für Bildung, Wissenschaft, Forschung und Technologie (BMFT) as part of the joint research programme on exchange and transformation processes in the Pomeranian Bay ('TRUMP'. 03F0105B). We are grateful to the Danish Institute for Fisheries Research for the laboratory facilities they provided. Dr Marie-Luise Hubert supported the statistical analyses. We thank Drs Paul Kähler, Thomas Kiørboe, Marcus Reckermann and Markku Viitasalo for critical comments on the manuscript.

\section{LITERATURE CITED}

Ahlgren G (1993) Seasonal variation of fatty acid content in natural phytoplankton in two eutrophic lakes. A factor controlling zooplankton species? Verh int Verein Theor Angew Limnol 25:144-149

Ahlgren G, Gustafsson IB. Boberg M (1992) Fatty acid content and chemical composition of freshwater microalgae. J Phycol 28:37-50

Ahlgren G, Lundstedt L, Brett M, Forsberg C (1990) Lipid composition and food quality of some freshwater phytoplankton for cladoceran zooplankters. J Plankton Res 12 : $809-818$

Brown M (1991) The amino-acid and sugar composition of 16 species of microalgae used in mariculture. J Exp Mar Biol Ecol 145:79-99

Burns CW, Forsyth DJ, Haney JF, James MR, Lampert W. Pridmore RD (1989) Coexistence and exclusion of zooplankton by Anabena minutissima var attenuata in Lake Rotongaio, New Zealand. Arch Hydrobiol Beih Ergeb Limnol 32:63-82

Burns CW, Xu Z (1990) Utilization of colonial cyanobacteria and algae by freshwater calanoid copepods: survivorship and reproduction of adult Boeckella spp. Arch Hydrobiol $117: 257-270$

Cowie GL, Hedges JI (1996) Digestion and alteration of biochemical constituents of a diatom (Thalassiosira weissflogii) ingested by an herbivorous zooplankton (Calanus pacificus). Limnol Oceanogr 41:581-594

DeMott WR (1989) Optimal foraging theory as a predictor of chemically mediated food selection by suspension-feeding copepods. Limnol Oceanogr 34:140-154

DeMott WR, Moxter F (1991) Foraging on cyanobacteria by copepods: responses to chemical defenses and resource abundance. Ecology 72:1820-1834

DeMott WR, Zhang QX, Carmichael WW (1991) Effects of toxic cyanobacteria and purified toxins on the survival and feeding of a copepod and three species of Daphnia. Limnol Oceanogr 36:1346-1357

Enright CT, Newkirk GF, Craigie JS, Castell JD (1986) Evaluation of phytoplankton as diets for juvenile Ostrea edulis (L.). J Exp Mar Biol Ecol 96:1-13

Frost BW (1972) Effects of size and concentration of food particles on the feeding behavior of the marine planktonic copepod Calanus pacificus. Limnol Oceanogr 17:805-815

Fulton RS, Paerl HW (1987a) Effects of coloniality on zooplankton utilization of resources during blue-green algal Microcystis aeruginosa blooms. Limnol Oceanogr 32: $634-644$

Fulton RS, Paerl HW (1987b) Toxic and inhibitory effects of the blue-green alga Microcystis aeruginosa on herbivorous zooplankton. J Plankton Res 9:837-855

Fulton RS, Paerl HW (1988) Zooplankton feeding selectivity for unicellular and colonial Microcystis aeruginosa. Bul] Mar Sci 43:500-508

Haney JF, Trout MA (1985) Size selective grazing by zooplankton in Lake Titicaca. Arch Hydrobiol Beih Ergeb Limnol 21:147-160

Harrison KE (1990) The role of nutrition in maturation, reproduction and embryonic development of decapod crustaceans: a review. J Shellfish Res 9:1-28

Holm NP. Shapiro JS (1984) An examination of lipid reserves and the nutritional status of Daphnia pulex fed Aphanizomenon flos-aquae. Limnol Oceanogr 28:677-687

Hoppe HG (1981) Blue-green algae agglomeration in surface water: a microbiotope of high bacterial activity. Kiel Meeresforsch, Sonderh 5:291-303 
Infante A (1978) Natural food of herbivorous zooplankton of Lake Valencia, Venezuela. Arch Hydrobiol 82:347-358

Jónasdóttir SH (1994) Elfects of food quality on the reproductive success of Acartia tonsa and Acartia hudsonica: laboratory observations. Mar Biol 121:67-81

Jónasdóttir SH, Kiørboe T (1996) Copepod rerruitment and food composition: do diatoms affect hatching success? Mar Biol 125:743-750

Kleppel GS, Burkart CA (1995) Egg production and the nutritional environment of Acartia tonsa: the role of food quality in copepod nutrition. ICES J Mar Sci 52:297-304

Lampert W (1981) Inhibitory and toxic effects of blue-green algae on Daphnia. Int Rev Ges Hydrobiol 66:285-298

Lampert W (1987) Laboratory studies on zooplanktoncyanobacteria interactions. NZ J Mar Freshwat Res 21: $483-490$

Meyer-Harms B (1996) Feeding strategy of calanoid copepods in two areas of the Baltic Sea of different trophic levels (Pomeranian Bight, Gotland Sea). Mar Sci Rep Baltıc Sea Res Inst 13

Nguyen RT, Harvey HR (1994) A rapid micro-scale method for the extraction and analysis of protein in marine samples. Mar Chem 45:1-14

Nizan S, Dimentman C, Shilo M (1986) Acute toxic effects of the cyanobacterium Microcystis aeruginosa on Daphnia magna. Limnol Oceanogr 31:497-502

O'Neil JM, Roman MR (1994) Ingestion of the cyanobacterium Trichodesmium spp by pelagic harpacticoid copepods Macrosetella, Mracia and Oculosetella. Hydrobiologia 292:235-240

Paerl HW (1988) Nuisance phytoplankton blooms in coastal, estuarine and inland waters. Limnol Oceanogr 33:823 8447

Paffenhofer GA, Van Sant KB (1985) The feeding response of a marine planktonic copepod to quantity and quality of particles. Mar Ecol Prog Ser 27:55-65

Pollehne F, Busch S, Jost G, Meyer-Harms B, Nausch M, Reckermann $M$, Schaening $P$, Setzkorn D, Wasmund $N$, Zbigniew W 11995) Primary production patterns and

This article was submitted to the editor heterotrophic use of organic material in the Pomeranian Bay (Southern Baltıc). Bul Morskiego Inst Rybackiego 3: $43-60$

Porter KG, Orcutt JD (1980) Nutritional adequacy, manageability, and toxicity as factors that determine food quality of green and blue-green algae for Daphnia. In: Kerfoot WC (ed) Evolution and ecology of zooplankton communities. University Press of New England. Hanover. p $268-281$

Roman MR (1984) Utilization of detritus by the copepod, Acartia tonsa. Limnol Oceanogr 29:949-959

Rothhdunt KO (1991) The influence of toxic and filamentous blue-green algae on feeding and population growth of the rotifer Brachionus rubens. Int Rev Ges Hydrobiol 76:67-72

Santer B (1994) Influences of food type and concentration on the der clopment of Eudiaptomus gracilis and implications for interactions between calanord and cyclopoid copepods. Arch Hydrobiol 131:141-159

Schindler JE (19,1) Food quality and zooplankton nutrition. J Anım Ecol 40:589-595

Støttrup JG, Richardson K, Kirkegaard E, Pihl NJ (1986) The cultivation of Acartia tonsa Dana for use as a live food source for marine fish larvae. Aquaculture 52:87-96

Vanderploeg HA, Paffenhöer GA, Liebig JR (1988) Diaptomus vs net phytoplankton: effucts of algal size and morphology on selectivity of a behariorally flexible, omnivorous copepod. Bull Mar Sci 43:377-394

Volkman JK, Jeffrey SW, Nichols PD, Rogers GI, Garland CD (1989) Fatty acid and lipid composition of 10 species of microalgae used in mariculture. J Exp Mar Biol Ecol 128: $219-240$

Watanabe T, Kitajuna C, Fujlta S (1983) Nutritional value of live organisms used in Japan for mass propagation of fish: a review. Aquaculture 34:115-143

Whyte JNC, Nagata WD (1990) Carbohydrate and fatty acid composition of the rotifer, Brachionus plicatılis, fed monospecific diets of yeast or phytoplankton. Aquaculture 89: $263-272$

Manuscript first received: December 9, 1996

Revised version accepted: March 14, 1997 
stances (VOS) isolated from Arenicola marina. Mar Ecol Prog Ser 139:157-166

Morris RJ, Dawson ME, Lockwood PM (1982) The identification of some lipophilic contaminants in the gill neutral lipids of Gammarus duebeni. Mar Pol] ut Bull 13:13-18

Nagata S (1982) Degradation of aliphatic and aromatic hydrocarbons by marine bacteria. Bull Jpn Soc Sci Fish 48: $781-786$

Napolitano GE, Ackman RG, Parrish CC (1992) Lipids and lipophilic pollutants in three species of migratory shorebirds and their food in Shepody Bay (Bay of Fundy, New Brunswick). Lipids 27:785-790

Parrish CC (1988) Dissolved and particulate marine lipid classes: a review. Mar Chem 23:17-40
Sakagami Y, Tanaka K, Watanabe K, Murooka H (1982b) Identification and characterization of the phthalate esterdegrading bacteria isolated from sea mud. Bull Jpn Soc Sci Fish 48:639-642

Sakagami Y, Tanaka K, Watanabe K, Odagiri M, Mon K, Murooka H (1982a) Isolation of bacteria which decompose phthalate esters from sea water and sea mud. Bull Jpn Soc Sci Fish 48:633-637

Shantha NC, Ackman RG (1.991) Behaviour of a common phthalate plasticizer (dioctyl phthalate) during the alkaliand/or acid-catalysed steps in an AOCS method for the preparation of methyl esters. J Chromatogr 587:263-267

Velimirov B (1982) Sugar and lipid components in sea foam near kelp beds. Mar Ecol 3:97-107

\section{ERRATUM}

\section{Nutritional quality of two cyanobacteria: How rich is 'poor' food?}

\section{K. Schmidt, S. H. Jónasdóttir}

Mar Ecol Prog Ser 151: 1-10, 1997

- Fig. 6 on page 8 contained an error-line 1 was incorrectly labelled. The corrected figure and its caption appear here.

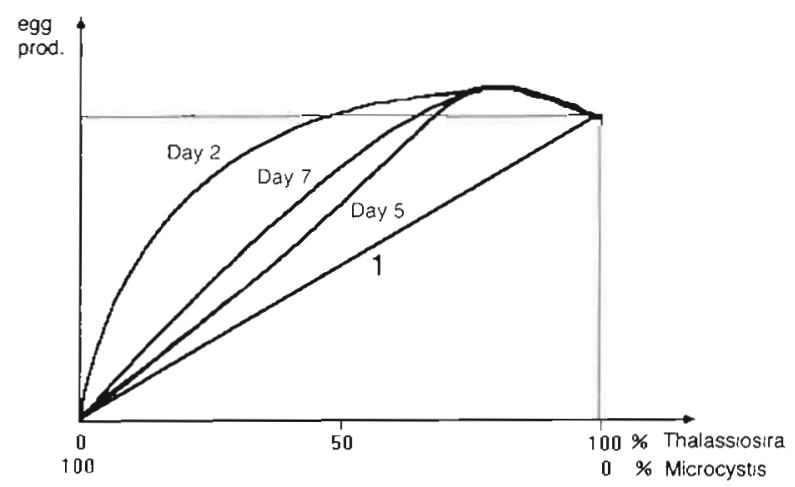

Fig. 6. A schematic presentation of our results in the ratio experiment; Days 2, 5 and 7 (compare Fig. 1). At all tested mixtures the measured egg production rates were above line 1 and indicate a positive effect of Microcystis aeruginosa on egg production. The nutritional benefit from $M$ aeruginosa is best shown at a proportion of $75 \%$ Thalassiosira weissflogii to $25 \% M$ aeruginosa. This mixture has a nutritional advantage compared to the pure diatom. During the first $4 \mathrm{~d}$ a running out of reserves from Rhodomonas baltica was evident at low and median proportions of $T$ weissflogii, but not at high proportions 